\title{
Representando a alteridade
}

Representando a Alteridade, de Angela Arruda ${ }^{l}$

\author{
Maria de Fátima de Souza Santos \\ Universidade Federal de Pernambuco
}

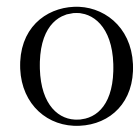

livro Representando a alteridade, organizado por Angela Arruda, vem preencher um espaço necessário às discussões em Psicologia Social. Reunindo pesquisadores cujas linhas de pesquisa são voltadas para temas diversos, ele consegue ter claramente um eixo central de discussão teórica: a contribuição da teoria das representações sociais ao campo das relações com o outro. Conceber o sujeito como produto e produtor social implica, necessariamente, ter como preocupação básica o estudo das relações que ele estabelece com o outro - entendidas como constitutivas do eu - e os sentidos que o outro assume nas diversas culturas.

Logo na apresentação do livro, entretanto, Moscovici chama a atenção do leitor para a distância que separa a aceitação desse pressuposto e as dificuldades que a noção do outro impõem. Dificuldades essas que abrangem a compreensão que se tem do que se denomina como outro, a gama de especificidades das relações que estabelecemos com o outro (por vezes, ausente ou negado em sua condição de sujeito) e o conjunto de idéias, noções e significados subjacentes à percepção imediata que temos do outro.

É considerando tais dificuldades que os autores tentam explorar a noção do outro a partir da teoria das representações sociais, articu- 
lando-a a outros conhecimentos produzidos na Psicologia e áreas afins. O leitor vai aos poucos observando a pluralidade de abordagens, o leque de possibilidades temáticas e, sobretudo, a necessidade de se explorar a noção de alteridade para melhor compreender a constituição do eu, a dinâmica das relações sociais e contribuir para o esclarecimento de ambigüidades e lacunas teóricas da teoria das representações sociais.

O capítulo de Angela Arruda sobre "O ambiente natural e seus habitantes no imaginário brasileiro" explora uma das facetas da alteridade: "a diferença que surpreende - o inusitado perturbador" para compreender o processo de ancoragem e de mudança de representações. Utilizando como fio condutor o encontro de grupos de diferentes culturas em relações desiguais de poder e situados em três momentos da história do Brasil - a colonização, a construção do Brasil-nação e a República, a autora vai discutir o processo de construção das representações da alteridade tentando apreender a dinâmica do desejo e do medo da diferença que estão na base da construção do outro e de si mesmo. Esse jogo, entretanto, é contextualizado. Ele é parte de uma trama que corresponde a necessidades coletivas, que têm como alicerce projetos políticos, econômicos, sociais e culturais. As mudanças dessas necessidades coletivas correspondem, segundo a autora, a mudanças nas representações hegemônicas. "A construção da alteridade e do mesmo se move ao compasso das conjunturas históricas", afirma Arruda. O texto deixa claro a dinâmica desse trabalho cognitivo e afetivo constante de construção e reconstrução das representações expressando relações de poder desiguais, conflitos de interesse e valores vigentes a cada época. Ele traz a discussão de aspectos ainda pouco explorados na literatura sobre representações sociais: o processo de ancoragem não apenas como a apropriação do novo a partir do familiar, mas como a busca do novo para o reordenamento do familiar. Neste sentido, o contexto social não aparece como pano de fundo, mas como elemento ativo na reestruturação do familiar, pressionando a incorporação do novo e provocando, assim, a mudança. Neste sentido, uma outra contribuição nos parece importante: a dinâmica das mudanças de representa- 
ções hegemônicas através dos tempos em um movimento teórico constante entre Psicologia, História, Sociologia e cultura.

O texto de Angela Arruda extrapola os estudos que "fotografam" um dado momento histórico e parecem cristalizar uma representação. Ela consegue transmitir ao leitor o jogo constante de idas e vindas presentes no cotidiano e a dinâmica proposta na teoria das representações sociais.

O segundo capítulo do livro apresenta um texto também instigante de Denise Jodelet: "A alteridade como produto e processo psicossocial". Utilizando a loucura como uma das faces da alteridade, Jodelet defende a idéia de que "a alteridade é produto de duplo processo de construção e de exclusão social que, indissoluvelmente ligados como os dois lados de uma folha, mantêm sua unidade por meio de um sistema de representações" (pp. 47-48).

A autora parte de uma distinção entre a "alteridade de fora", isto é, o que é distante, exótico com relação a uma determinada cultura e a "alteridade de dentro", no sentido das diferenças dentro de um mesmo conjunto cultural ou social. Ela acrescenta, entretanto, a necessidade de se apreender os diversos patamares que se estabelecem nas relações com o outro, os diferentes graus de proximidade desse outro numa realidade social. Aquele que não é o mesmo que "nós" pode ser apenas diferente, mas próximo, ou constituir-se como um alter em "sua forma mais extrema e alienante" como é no caso do racismo e, certamente, de todas as formas de exclusão social. O artigo traz uma contribuição importante ao tratar a questão eu-outro sob a ótica das diferentes formas de sociabilidade, destacando a necessidade de se compreender a diversidade de manifestações concretas que assume a relação com o outro na vida cotidiana a partir das pertenças sociais. Para a autora, são as pertenças grupais que sustentam os processos simbólicos e materiais responsáveis pela construção da alteridade. Disso decorre a necessidade de se estudar a alteridade sempre levando em consideração os níveis interpessoais e intergrupais. Jodelet defende a idéia de que a alteridade "só pode ser analisada tendo como pano de fundo as condições que estruturam as relações sociais, em um contexto plural" (p. 65). O exemplo dado 
com o seu estudo sobre a loucura abre as portas para inúmeras reflexões sobre o papel das representações na construção da identidade e da diferença/alteridade, contribuindo também para o estudo da exclusão social.

Sandra Jovchelovitch inicia sua discussão centrando seu olhar sobre a importância da consciência do outro no processo de construção dos significados. Baseando-se na teoria de Piaget, ela demonstra que o conhecimento simbólico é, em sua gênese, um conhecimento interativo. Ele envolve o reconhecimento de diferenças e o desejo de relacionar-se com essas diferenças. A mediação do outro é fundamental para que o eu possa refletir sobre si mesmo e constituir-se como objeto de conhecimento. A partir dessa discussão, o artigo "Re (des) cobrindo o outro" vem nos colocar uma série de questões sobre o reconhecimento do outro como um ser de desejos, de projetos e perspectivas próprias. O outro não se esgota no conjunto de significados construídos pelo eu. A "resistência ativa do outro" introduz a objetividade no mundo do simbólico, da subjetividade. Portanto, o simbólico não pode ser confundido com o objeto ele mesmo e não pode esgotá-lo, ele apenas representa o objeto. Jovchelovitch traz à tona uma discussão bastante atual no âmbito da Psicologia Social: a total intersecção entre o objeto e o ato significativo. A representação seria o próprio objeto ou o ato de representar, mesmo dando forma e existência ao objeto, não o esgotaria totalmente? A autora defende a posição de que representar não pode ser confundido com o próprio objeto, mesmo porque ao dar significados os sujeitos se deparam com os limites de outros sujeitos, de uma pluralidade de significados atribuídos pelo outro. É no espaço da intersubjetividade que são construídos os sentidos. É, portanto, no espaço intersubjetivo que se negocia a objetividade. Essa negociação é realizada permanentemente na ação comunicativa. Para a autora, ação simbólica, intersubjetividade, objetividade e identidade são elementos essenciais na compreensão do processo de construção do eu e da realidade social. E é desse jogo que emergem as representações sociais produzindo um sistema de conhecimento coletivo, capaz tanto de conferir uma identidade 
social a um grupo dado, como de produzir formas de enfrentamento do cotidiano e de relacionamento com os objetos.

Também preocupado com o processo de construção das representações sociais, Gerard Duveen aborda o tema sob a perspectiva genética. Partindo de uma análise crítica das proposições piagetianas, ele busca aprofundar o papel constitutivo dos outros e a alteridade no surgimento e funcionamento das representações sociais. Utiliza como fio condutor da discussão teórica o desenvolvimento da identidade de gênero na criança. Para ele, o desenvolvimento psicológico é um processo social e exige, portanto, que se tenha o estudo da identidade como foco principal. Posiciona-se também de forma crítica com relação à teoria da identidade social de Tajfel, afirmando que essa teoria refere-se às conseqüências da categorização sem, entretanto, esclarecer os motivos pelos quais os sujeitos se classificam desta ou daquela maneira. Para Duveen, a identidade é um lugar social, "um espaço que se torna disponível dentro das estruturas representacionais do mundo social." (p. 98). O autor analisa a construção da identidade de gênero em crianças utilizando a brincadeira do faz-de-conta como espaço privilegiado de estudo da construção da representação, uma vez que essa brincadeira emerge dos esforços de cooperação das crianças. Nessa perspectiva, o esforço construtivo da criança para entender o mundo social gera e mantêm representações que são encenadas no jogo do faz-de-conta.

Já o capítulo de Helene Joffe nos leva a refletir sobre a possibilidade de construção de uma teoria a respeito da estrutura dos conteúdos utilizados em explicações dadas por sujeitos para as situações de crises surgidas em seu mundo social (crises epidêmicas, políticas, ambientais e econômicas), utilizando em sua análise o suporte das teorias psicodinâmicas e antropológicas. Questiona a suposição dos teóricos culturalistas de que apenas os grupos dominantes representariam os grupos dominados de forma depreciativa, destituídos de sua humanidade, em um processo que mescla a forte depreciação e o desejo do outro. Baseando-se em resultados de pesquisas com sujeitos ocidentais e não-ocidentais e entre grupos dominados, Joffe vai nos conduzindo à compreensão da possibilidade de existência de um 
"padrão simétrico de respostas à crise". A ansiedade é tomada como um conceito organizador. Para a autora, em situações de crise e ameaça há um "reavivamento da resposta primitiva", infantil, onde mau e bom são separados através da introjeção dos aspectos positivos e da projeção dos aspectos negativos. Esse padrão de pensamento estaria presente nas situações de crise, situações ameaçadoras por excelência. Os grupos (hegemônicos ou não) projetariam no outro as características indesejadas mantendo, assim, sentimentos positivos de si mesmo. Ressalta ainda a autora que esse processo ocorre em um clima ideológico preciso, que irá favorecer a emergência de certas práticas e pensamentos em detrimento de outros. $\mathrm{O}$ texto de Joffe tem ainda o mérito de tentar articular cognição e afeto no quadro social.

O capítulo "Loucura, multiplicidade e alteridade" de Nicola Morant e Diana Rose, trata de um objeto social específico - a loucura - que nos leva também a questionar um aspecto importante da teoria das representações sociais: o processo de ancoragem. Em sua proposição inicial, a ancoragem tem a função de transformar o não-familiar em familiar. Entretanto, as autoras põem em questão esse pressuposto no que se refere ao objeto doença mental. $\mathrm{O}$ excesso de significados atribuídos à loucura e a ambigüidade presente na significação tornam o objeto resistente a uma classificação segura, tanto em seu conteúdo quanto em sua forma. A loucura permanece como ameaçadora e imprevisível e, mesmo quando distanciada, projetada no outro, ela não se torna familiar. As autoras concluem que a especificidade desse objeto social levanta uma questão teórica importante: a representação social não elimina a não-familiaridade. Além disso, consideram a não-familiaridade como uma noção complexa que necessita de maiores investimentos teóricos para seu desvendamento.

Finalmente, Pedrinho Guareschi nos convida a refletir com ele sobre alguns conceitos básicos da Psicologia e suas implicações. As diferentes concepções de ser humano, o conceito de relação e os temas de ética, justiça e alteridade deveriam, segundo o autor, ser mais discutidos na Psicologia, embora reconheça a complexidade e dificuldades inerentes a tal discussão. Guareschi parte de uma definição 
de relação como "o ordenamento (intrínseco) de uma coisa com relação a outra" (p. 156) para postular uma concepção de ser humano como relação, isto é, a pessoa é um, é diferenciado, mas para ser necessita dos outros. "Somos como que um ancoradouro para onde chegam milhares de naus" (p.153). Ou, como diria a personagem Bel do livro infantil de Ana Clara Machado (Bisa Bia, Bisa Bel), a pessoa é uma enorme "trança de gente".

A concepção de pessoa como relação traz conseqüências que remetem imediatamente às práticas relativas ao outro e suas implicações éticas. $\mathrm{O}$ outro é assim concebido como uma identidade distinta "mas que estabelece com o mesmo uma relação de diálogo, construtiva, de conversão" (p. 157). Uma outra conseqüência dessa concepção está presente na proposta de Guareschi em utilizar o método analético para compreender o mundo, as pessoas e pensar em práticas sociais que tragam em si uma dimensão ética.

A leitura dos diferentes artigos remete a questões instigantes e ressalta a necessidade de nos debruçarmos sobre o tema da alteridade se quisermos compreender a pessoa humana e a construção da realidade social. Restam-nos inúmeras questões a serem aprofundadas tanto no que concerne ao tema alteridade quanto aos diferentes aspectos teóricos a serem esclarecidos nas propostas contidas na teoria das representações sociais. Porém, parafraseando Moscovici na apresentação do livro, "um grupo começa com três" e o esforço conjunto dos autores reunidos é um excelente começo.

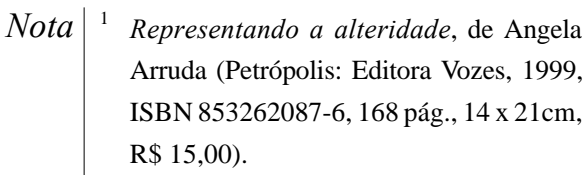

Maria de Fátima de Souza Sobre a autora Santos, doutora em Psicologia Social pela Universidade de Toulouse 
382 Resenha

Le Mirail (França), é professora do Departamento de Psicologia da Universidade Federal de Pernambuco.

Endereço para correspondência: Rua Ibiá, 70, Bairro Casa Amarela, 52051-300, Recife, PE.

E-mail: mfssantos@npd.ufpe.br. 